\title{
Effects of terpineol on the compound action potential of the rat sciatic nerve
}

M.R. Moreira,

A.A.C. Albuquerque and J.H. Leal-Cardoso

\author{
Centro de Ciências da Saúde, Universidade Estadual do Ceará, \\ Fortaleza, CE, Brasil
}

\section{Correspondence \\ J.H. Leal-Cardoso \\ Centro de Ciências da Saúde \\ Universidade Estadual do Ceará \\ Av. Paranjana, 1700 \\ Campus Itaperí \\ 60740-000 Fortaleza, CE \\ Brasil}

Presented at the XV Annual Meeting of the Federação de Sociedades de Biologia Experimental, Caxambu, MG, Brazil, August 23-26, 2000.

Received April 14, 2000

Accepted July 6, 2001

\section{Abstract}

Terpineol, a volatile terpenoid alcohol of low toxicity, is widely used in the perfumery industry. It is an important chemical constituent of the essential oil of many plants with widespread applications in folk medicine and in aromatherapy. The effects of terpineol on the compound action potential (CAP) of rat sciatic nerve were studied. Terpineol induced a dose-dependent blockade of the CAP. At $100 \mu \mathrm{M}$, terpineol had no demonstrable effect. At $300 \mu \mathrm{M}$ terpineol, peak-topeak amplitude and conduction velocity of CAP were significantly reduced at the end of 180-min exposure of the nerve to the drug, from $3.28 \pm 0.22 \mathrm{mV}$ and $33.5 \pm 7.05 \mathrm{~m} / \mathrm{s}$, respectively, to $1.91 \pm 0.51 \mathrm{mV}$ and $26.2 \pm 4.55 \mathrm{~m} / \mathrm{s}$. At $600 \mu \mathrm{M}$, terpineol significantly reduced peakto-peak amplitude and conduction velocity from $2.97 \pm 0.55 \mathrm{mV}$ and $32.8 \pm 3.91 \mathrm{~m} / \mathrm{s}$ to $0.24 \pm 0.23 \mathrm{mV}$ and $2.72 \pm 2.72 \mathrm{~m} / \mathrm{s}$, respectively $(\mathrm{N}$ $=5$ ). All these effects developed slowly and were reversible upon 180min washout.

Terpineol, a relatively nontoxic, volatile monoterpenoid alcohol, is a major component of the essential oil of many plants, such as Ravensara aromatica (Ravensara), Melaleuca qinquenervia (Niaouli), Myrtus communis (Myrtle), Laurus nobilis (Laurel), Croton sonderianus (Marmeleiro preto, in Northeastern Brazil), and Eucalyptus globulus (Eucalyptus), which are widely used in folk medicine and aromatherapy $(1,2)$. This compound is also a constituent of some inhalants and syrups marketed over-the-counter (3). Some of the biological actions of terpineol have been studied. The compound has been reported to have insecticidal, antimicrobial, antispasmodic and immunostimulant properties and to enhance the permeability of the

\section{Key words}

- Essential oil

- Alpinia speciosa

- Zingiberaceae

- Sciatic nerve

- Compound action potential

- Nerve conduction velocity skin to lipid-soluble compounds $(2,4,5)$.

Many essential oils and their chemical constituents are known to have potent local anesthetic activity (6-8). Because no previous pharmacological studies with terpineol had examined its effects on peripheral nerve electrophysiology, the present study aimed at characterizing the actions of terpineol on the compound action potential (CAP).

Wistar rats (Rattus norvegicus; 300-350 g) were sacrificed by cervical dislocation and the sciatic nerves were carefully dissected. One nerve was then mounted in a moist chamber (9) and one of its ends was stimulated at a frequency of $0.2 \mathrm{~Hz}$ with electric pulses of 50-100- $\mu$ s duration at 10 $20 \mathrm{~V}$ delivered by a stimulus isolation unit 
(Model SIU4678, Grass Instruments Co., Quincy, MA, USA), connected to a stimulator (Model S48, Grass). Evoked CAP were recorded with platinum electrodes placed 4 to $5 \mathrm{~cm}$ from the stimulating electrodes. For continuous monitoring, these electrodes were connected through a high input impedance amplifier (Model P15, Grass) to an oscilloscope (Model 547, Tektronix, Inc., Portland, OR, USA). Digidata 1200 computer acquisition hardware (Axon Instruments, Inc., Foster City, CA, USA) and AxoScope software (Axon) were used for data capture and analysis. A 15- to 20-mm segment of the nerve suspended between the stimulating and recording electrodes was immersed in Locke's solution which was employed to maintain chamber humidity. Pharmacological agents were dissolved in Locke's solution and administered via the bathing solution.

After a stabilization period of $60 \mathrm{~min}$, during which stable peak-to-peak CAP amplitude recording was performed for at least $30 \mathrm{~min}$, the bathed nerve segment was exposed to pharmacological agents for 180 min. This interval was usually sufficient to allow steady-state action potential amplitude to be reached during terpineol administration. This period was followed by a wash- out and a 180-min recovery period. Experiments were carried out at room temperature $\left(24^{\circ}-26^{\circ} \mathrm{C}\right)$.

Modified Locke's solution $(140 \mathrm{mM}$ $\mathrm{NaCl}, 5.6 \mathrm{mM} \mathrm{KCl}, 2.2 \mathrm{mM} \mathrm{CaCl}, 1.2 \mathrm{mM}$ $\mathrm{MgCl}_{2}, 10 \mathrm{mM}$ glucose, and $10 \mathrm{mM}$ Tris(hydroxymethyl)aminomethane), $\mathrm{pH}$ 7.4, was thoroughly aerated before use in the chamber. Nerves were normally used on the day of dissection; however, in some experiments they were stored overnight in cold $\left(5^{\circ} \mathrm{C}\right)$ Locke's solution for use on the following day. This storage period did not affect nerve electrophysiological control parameters.

Stock solutions of terpineol in dimethylsulfoxide (DMSO, vehicle) were prepared daily. This stock solution was added to the chamber Locke's solution so as to provide the desired terpineol concentration with a final vehicle concentration always below $0.25 \%(\mathrm{v} / \mathrm{v})$. At such concentration DMSO did not alter CAP parameters. All salts and drugs, including terpineol, were purchased from Sigma (St. Louis, MO, USA), or Reagen (Rio de Janeiro, RJ, Brazil) and were of analytical grade.

The results are reported as mean $\pm \mathrm{SEM}$, with $(\mathrm{N})$ indicating the number of experiments. The values were analyzed using the

Table 1. Effects of terpineol (TER) on the peak-to-peak amplitude and conduction velocity of the compound action potential (CAP) of the rat sciatic nerve.

\begin{tabular}{|c|c|c|c|c|c|c|}
\hline \multirow{2}{*}{$\begin{array}{l}\text { TER concentration } \\
(\mu \mathrm{M})\end{array}$} & \multicolumn{3}{|c|}{ Peak-to-peak amplitude (mV) } & \multicolumn{3}{|c|}{ Velocity of CAP conduction (m/s) } \\
\hline & Control & $\begin{array}{l}\text { At 180th } \\
\text { min in TER }\end{array}$ & Recovery & Control & $\begin{array}{l}\text { At 180th } \\
\text { min in TER }\end{array}$ & Recovery \\
\hline 0 & $\begin{array}{c}4.5 \pm 0.12 \\
\text { (5) }\end{array}$ & - & $\begin{array}{l}4.4 \pm 0.13^{b} \\
(5)\end{array}$ & $\begin{array}{c}33.3 \pm 2.70 \\
(5)\end{array}$ & - & $\begin{array}{c}32.9 \pm 1.45 \\
(5)\end{array}$ \\
\hline 100 & $\begin{array}{c}3.3 \pm 0.12 \\
(5)\end{array}$ & $\begin{array}{c}3.4 \pm 0.17 \\
(5)\end{array}$ & - & $\begin{array}{c}32.5 \pm 3.99 \\
(5)\end{array}$ & $\begin{array}{c}32.8 \pm 5.56 \\
\text { (5) }\end{array}$ & - \\
\hline 300 & $\begin{array}{c}3.3 \pm 0.22 \\
(5)\end{array}$ & $\begin{array}{c}1.9 \pm 0.51 \\
(5)\end{array}$ & $\begin{array}{c}3.0 \pm 0.27 \\
(2)\end{array}$ & $\begin{array}{c}33.5 \pm 7.05 \\
(5)\end{array}$ & $\begin{array}{c}26.2 \pm 4.55 \\
(5)\end{array}$ & $\begin{array}{c}30.5 \pm 4.71 \\
\text { (2) }\end{array}$ \\
\hline 600 & $\begin{array}{c}3.0 \pm 0.55 \\
\text { (5) }\end{array}$ & $\begin{array}{c}0.2 \pm 0.23 \\
(5)\end{array}$ & $\begin{array}{c}1.9 \pm 0.06 \\
(2)\end{array}$ & $\begin{array}{c}32.8 \pm 3.91 \\
(5)\end{array}$ & $\begin{array}{c}2.7 \pm 2.72 \\
(4)^{c}\end{array}$ & $\begin{array}{c}20.0 \pm 2.55 \\
\text { (2) }\end{array}$ \\
\hline
\end{tabular}

Data are reported as mean \pm SEM. The number of observations is given in parentheses. aQuantification at $180 \mathrm{~min}$.

bControl (0.25\% DMSO), at the 360th min after stabilization.

${ }^{\mathrm{C}} \mathrm{N}=4$ because in one experiment CAP blockade was total after $120 \mathrm{~min}$. 
Student $t$-test, or ANOVA followed by a contrast test, or a nonparametric test, as appropriate. Results were considered significant at $\mathrm{P} \leq 0.05$.

At $100 \mu \mathrm{M}$, terpineol did not alter the CAP (Table 1 and Figure 1), but at doses of 300 and $600 \mu \mathrm{M}$, peak-to-peak amplitude and conduction velocity were significantly reduced in a dose-dependent manner (Table 1 and Figure 1). These effects developed slowly and were reversible within the 180 min recovery period.

Terpineol has been previously shown to increase the absorption of lipid-soluble substances through the skin, and to possess antimicrobial, antispasmodic and immunostimulant properties $(1,2)$. The present finding that terpineol blocks the CAP propagation of rat sciatic nerve is novel. This terpineolinduced blockade of nerve action potentials occurs at relatively low concentrations (300 $\mu \mathrm{M})$. This concentration is approximately equivalent to a $0.005 \%(\mathrm{v} / \mathrm{v})$ solution. In aromatherapy massages a volume of $5-25 \mathrm{ml}$ of a concentrated ( 1 to $5 \%, \mathrm{v} / \mathrm{v}$ ) solution of essential oil in an oily vehicle is commonly used (3). As much as $25 \%$ of the essential oil may be absorbed through the skin during the massage (3) and terpineol comprises up to $30 \%$ of some oils (10). Thus, terpineol concentrations in the range of 300 to $600 \mu \mathrm{M}$ might be reached in dermal tissues during massages with essential oils rich in terpineol.

Since terpineol is an important constituent of many essential oils, some of them used in aromatherapy, it is important to understand the physiological effects of oil constituents and of the potential for accidental intoxication. Blockade of action potentials in peripheral nerves raises the question of whether this blocking effect might be induced by aromatherapy in peripheral nerve terminals or other nerve segments and, if so, what contribution it might add to treatment. Moreover, the effect of terpineol on nerve action potentials suggests that it may also affect other excitable tissues such as muscle. The effect of terpineol on excitable tissues thus deserves further investigation.

Action potential blockade was demonstrated with the quantification of the CAP parameters, conduction velocity and peak-

$$
\text { A }
$$

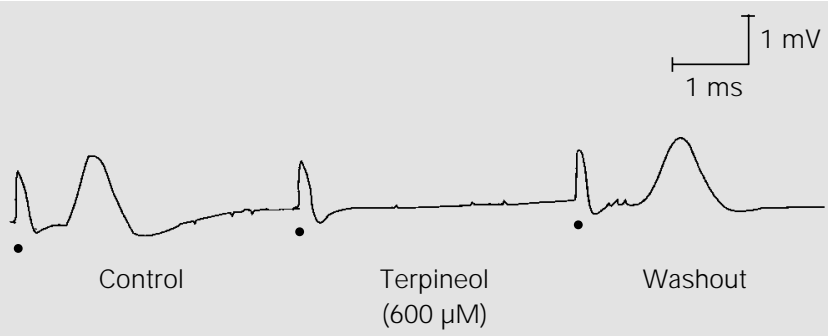

B

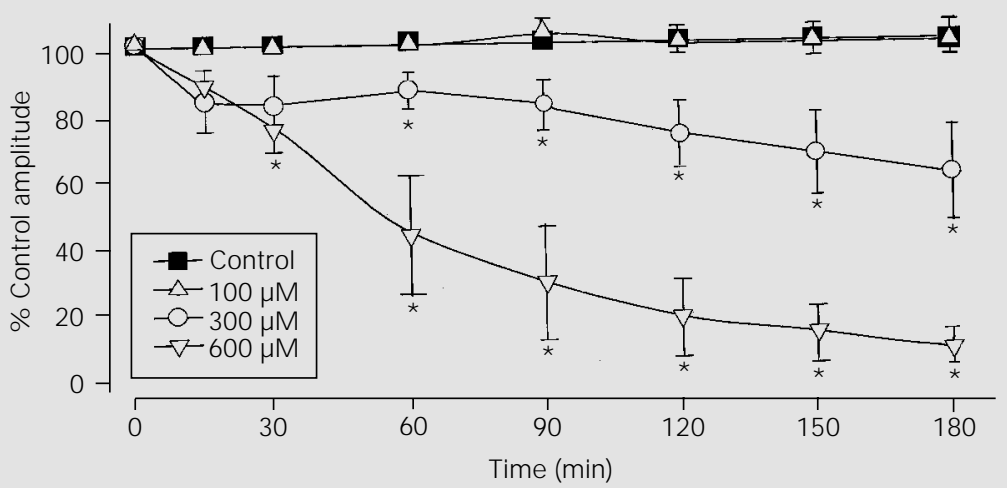

C

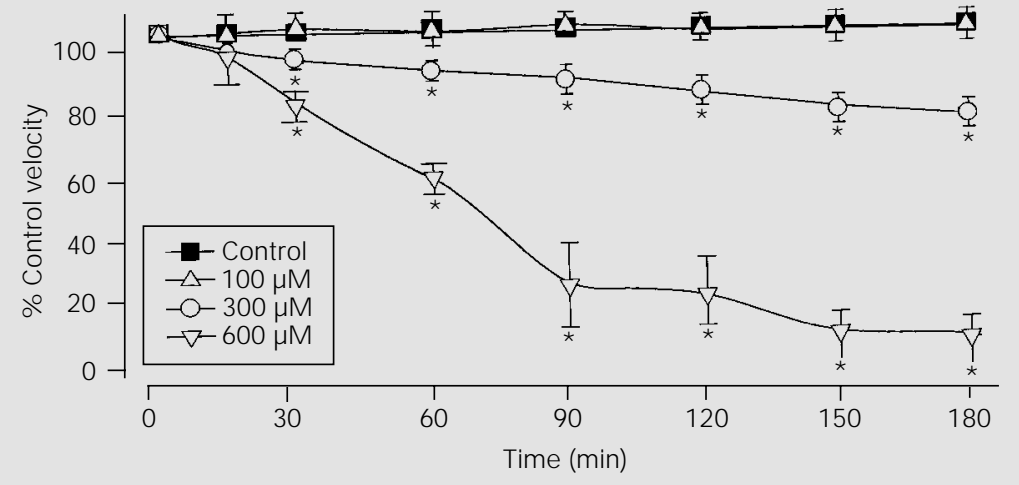

Figure 1. Time course of the effects of terpineol on peak-to-peak amplitude and conduction velocity of the compound action potential (CAP) of rat sciatic nerve. Panel A shows representative CAP tracings under control conditions and at the 180th min of nerve exposure to $600 \mu \mathrm{M}$ terpineol and at $180 \mathrm{~min}$ washout. The dot below each tracing shows the time of stimulation. Quantification of terpineol-induced effect on peak-to-peak amplitude and conduction velocity is shown in panels $B$ and $C$, respectively. Data are reported as mean \pm SEM. The number of experiments was 5 in all cases, except for conduction velocity for $600 \mu \mathrm{M}$ terpineol at 150 and 180 min where $\mathrm{N}$ was 4 since blockade was complete in one of the experiments. $* \mathrm{P}<0.05$ compared to control (ANOVA and contrast technique test). 
to-peak amplitude. Control values reported here for both parameters are well within the range reported by others in peripheral nerve recordings in vitro at room temperature and in vivo at $37^{\circ} \mathrm{C}$, which ranged from 100 to 16 $\mathrm{m} / \mathrm{s}$ (11-14). The preparation showed great stability $(6 \mathrm{~h})$ which permitted us to demonstrate that, at concentrations $\geq 300 \mu \mathrm{M}$, terpineol induced a reversible blockade of the action potential conduction. Another important monoterpenoid constituent of essential oils, eugenol, whose molecular structure bears similarity to terpineol, also blocks the nerve action potential with a similar potency, but with a reversibility that has been questioned (15). Terpineol blocked the CAP and this fulfills one criterion for local anesthetic activity (16), but other criteria, like direct drug interaction with voltage-gated $\mathrm{Na}^{+}$channels and absence of significant or consistent alteration of resting potential, need to be investigated to characterize this substance as a local anesthetic agent.

\section{References}

1. Craveiro AA, Fernandes AG, Andrade CHS, Matos FJ A, Alencar J W \& Machado MIL (1981). Óleos Essenciais de Plantas do Nordeste. Edições UFC, Fortaleza, CE, Brazil.

2. Franchome $P \&$ Penoel D (1995). L'Aromathérapie Exactement: Encyclopedie de I'Utilisation Thérapeutique des Huiles Essentielles. Roger J ollois Edition, Limoges, France.

3. Tisserand R \& Balacs T (1995). Essential Oil Safety: A Guide for Health Care Professionals. Churchill Livingstone, New York.

4. Williams AC \& Barry BW (1991). Terpenes and the lipid-protein-partitioning theory of skin penetration enhancement. Pharmaceutical Research, 8: 17-24.

5. Lee $S$, Tsao R, Peterson $C \&$ Coats JR (1997). Insecticidal activity of monoterpenoids to western corn rootworm (Coleoptera: Chrysomelidae), twospotted spider mite (Acari: Tetranychidae), and house fly (Diptera: Muscidae). J ournal of Economic Entomology, 90: 883-892.
6. Brodin P \& Roed A (1984). Effects of eugenol on rat phrenic nerve and phrenic nerve-diaphragm preparations. Archives of Oral Biology, 29: 611-615.

7. Dallmeier K \& Carlini EA (1981). Anesthetic, hypothermic, myorelaxant and anticonvulsant effects of synthetic eugenol derivates and natural analogues. Pharmacology, 22: 113-127.

8. Ghelardini C, Galeotti N, Salvatore G \& Mazzanti G (1999). Local anesthetic activity of the essential oil of Lavandula angustifolia. Planta Medica, 65: 700-703.

9. Petrán M (1967). Electrophysiological apparatus and technique. In: Bures J , Petrán M \& Zachar J (Editors), Electrophysiological Methods in Biological Research. Academic Press, New York, 40-270.

10. Silva AR (1998). Tudo Sobre Aromaterapia. Editora C. Roka Ltda., São Paulo.

11. Gasser HS (1943). Pain-producing impulses in peripheral nerves. Proceedings of the Association for Research in Nervous and Mental Disease, 23: 44-62.

12. Zachar J (1967). Electrophysiology of iso- lated excitable structures in vitro. In: Bures J , Petrán M \& Zachar J (Editors), Electrophysiological Methods in Biological Research. Academic Press, New York, 304-386.

13. Miyoshi T \& Goto I (1973). Serial in vivo determinations of nerve conduction velocity in rat tails: Physiological and pathological changes. Electroencephalography and Clinical Neurophysiology, 35: 125131.

14. Shindo H, Tawata M \& Onaya T (1992). Reduction of cyclic AMP in the sciatic nerve of rats made diabetic with streptozotocin and the mechanism involved. J ournal of Endocrinology, 136: 431-438.

15. Kozam G (1977). The effect of eugenol on nerve transmission. Oral Surgery, Oral Medicine, Oral Pathology, 44: 799-805.

16. Catterall WA \& Longnecker DE (1996). Local anesthetics. In: Hardman JG \& Limbird LE (Editors), Goodman \& Gilman's The Pharmacological Basis of Therapeutics. 9th edn. McGraw-Hill, New York, 331-347. 